\title{
Star-configured carbazole as an efficient near-ultraviolet emitter and hole-transporting material for organic light-emitting devices
}

\author{
Hai-Feng Xiang, ${ }^{1}$ Zong-Xiang Xu, ${ }^{1}$ V. A. L. Roy ${ }_{3}^{1}$ Chi-Ming Che, ${ }_{3}^{1, a)}$ P. T. Lai, ${ }^{2}$ \\ Peng-Ju Zeng, ${ }^{3, b)}$ Fang-Fang Niu, ${ }^{3}$ Ya-Wei Liu, ${ }^{3}$ Wei-Qun Tang, ${ }^{3}$ Cai-Jie He, ${ }^{3}$ and \\ Han-Ben $\mathrm{Niu}^{3}$ \\ ${ }^{1}$ Department of Chemistry and HKU-CAS Joint Laboratory on New Materials, The University of \\ Hong Kong, Pokfulam Road, Hong Kong SAR, People's Republic of China \\ ${ }^{2}$ Department of Electrical and Electronic Engineering, The University of Hong Kong, Pokfulam Road, \\ Hong Kong SAR, People's Republic of China \\ ${ }^{3}$ Institute of Optoelectronics, College of Optoelectronics Engineering, Shenzhen University, Shenzhen, \\ People's Republic of China
}

(Received 30 November 2007; accepted 17 January 2008; published online 20 February 2008)

\begin{abstract}
A novel organic material, 9-methyl-1,3,6,8-tetraphenyl-carbazole (MTPC-Me), for use in organic electroluminescent devices has been developed. This star-configured carbazole gives a strong near-ultraviolet $(\mathrm{n}-\mathrm{UV})$ emission $\left(\lambda_{\max }=389 \mathrm{~nm}\right)$ with a high emission quantum efficiency of $47 \%$ and a narrow full width half maximum of $40 \mathrm{~nm}$. Two types of high-performance organic light-emitting devices were obtained using MTPC-Me as a n-UV emitter and hole-transporting material with maximum external quantum efficiency, brightness, and turn-on voltage of $1.2 \%$, $1040 \mathrm{~cd} / \mathrm{m}^{2}$, and $3.5 \mathrm{~V}$ for the former and $1.1 \%, 18000 \mathrm{~cd} / \mathrm{m}^{2}$, and $2.4 \mathrm{~V}$ for the latter, respectively. (C) 2008 American Institute of Physics. [DOI: 10.1063/1.2841063]
\end{abstract}

The performance of red-to-blue organic light-emitting devices (OLEDs) has improved dramatically over the past decade. ${ }^{1-4}$ However, extending OLED emission into the ultraviolet (UV) or near-ultraviolet (n-UV) wavelength is still challenging, despite the useful applications of n-UV OLEDs as an excitation light source for red-to-blue or white luminescence conversion and in high-density information storage devices. In addition, UV or n-UV emitters are widely used as a host material for triplet dopant emitters in phosphorescent OLEDs. ${ }^{5,6}$ To date, only several n-UV emitters, such as $4,4^{\prime}-N, N^{\prime}$-dicarbazole-biphenyl (CBP), ${ }^{7} \quad N, N^{\prime}$-diphenyl- $N, N^{\prime}$-bis(3-methylphenyl)(1,10biphenyl)-4, $4^{\prime}$-diamine (TPD), ${ }^{8,9}$ and bi(9,9-diarylfluorene)s, ${ }^{10}$ have been proven to be effective UV or n-UV emitters for OLEDs.

Functionalized carbazoles have played an important role in OLEDs as a host material ${ }^{11,12}$ and hole-transporting material (HTM). ${ }^{13,14}$ Here, we report efficient $n-U V$ emission with narrow full width half maximum (FWHM) from a novel 1,3,6,8-substituted carbazole derivative, 9-methyl-1,3,6,8tetraphenyl-carbazole (MTPC-Me), the structure of which is shown in Fig. 1. Two types of high-performance OLEDs have been fabricated by using this star-configured MTPC-Me carbazole as a n-UV emitter and HTM.

The preparation method of MTPC-Me will be described elsewhere. The characteristic data of this compound are as follows: $\mathrm{mp}, 236.2{ }^{\circ} \mathrm{C}$; $\mathrm{MS}-\mathrm{EI}(\mathrm{m} / \mathrm{e}), 485\left(\mathrm{M}^{+}\right.$, $100.00 \%), 486(30 \%), 243$ (15\%); elemental analyses: calculated percentage for $\mathrm{C}_{37} \mathrm{H}_{27} \mathrm{~N}$ : C $91.51 \%, \mathrm{H} 5.60 \%, \mathrm{~N}$ $2.88 \%$; found: $\mathrm{C} 91.20 \%, \mathrm{H} 5.56 \%$, N 2.68\%; ${ }^{1} \mathrm{H} \mathrm{NMR}\left(\mathrm{CDCl}_{3}, 500 \mathrm{~Hz}\right) \delta: 2.94(3 \mathrm{H}, s), 7.38-7.42(4 \mathrm{H}, m)$, $7.47-7.52(8 \mathrm{H}, q), \quad 7.60-7.65(2 \mathrm{H}, m), \quad 7.80-7.81(4 \mathrm{H}, t)$,

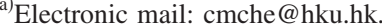

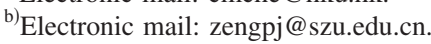

$8.42-8.42(2 \mathrm{H}, d)$. Three different types of OLEDs were fabricated:

device A: indium-tin oxide (ITO)/MTPC-Me $(50 \mathrm{~nm}) / \mathrm{Alq}_{3}(50 \mathrm{~nm}) / \mathrm{LiF}(0.5 \mathrm{~nm}) / \mathrm{Al}(100 \mathrm{~nm})$, device B: ITO/NPB $(50 \mathrm{~nm}) / \mathrm{Alq}_{3} \quad(50 \mathrm{~nm}) / \mathrm{LiF} \quad(0.5 \mathrm{~nm}) / \mathrm{Al}$ $(100 \mathrm{~nm})$, and device $\mathrm{C}$ : ITO/CuPc $(30 \mathrm{~nm}) / \mathrm{MTPC}-\mathrm{Me}$ $(30 \mathrm{~nm}) / \mathrm{BCP} \quad(10 \mathrm{~nm}) / \mathrm{Alq}_{3} \quad(30 \mathrm{~nm}) / \mathrm{LiF} \quad(0.5 \mathrm{~nm}) / \mathrm{Al}$ $(100 \mathrm{~nm})$, where ITO glass is transparent anode; copper(II) phthalocyanine $(\mathrm{CuPc})$ is hole-injecting material; $N, N^{\prime}$-bis(naphthyl)- $N, N^{\prime}$-diphenyl-1, 1' -biphenyl-4, 4' -diamine (NPB) is HTM; 2,9-dimethyl-4,7-diphenyl-1,10phenanthroline (BCP) is hole-blocking material (HBM); and tris-(8-hydroxyquinolato) aluminum(III) $\left(\mathrm{Alq}_{3}\right)$ is electrontransporting material (ETM) or emitting material (EM). In this work, all OLEDs were prepared ${ }^{15,16}$ on patterned ITO glass with a sheet resistance of $20 \Omega / \square$. All layers of the OLEDs were grown by thermal evaporation under a vacuum of $1 \times 10^{-6}$ Torr. The device performance was examined using Photoresearch PR-650 and Keithley 2400 source meter. All chemicals were sublimed before use.

We have not been able to obtain crystals of MTPC-Me with quality good enough for single crystal x-ray structure determination. Nevertheless, we have obtained crystals of its analog 9-ethyl-1,3,6,8-tetraphenyl-carbazole (MTPC-Et) and determined its crystal structure. As depicted in Fig. 2, due to the four phenyl groups, MTPC-Et is sterically bulky with a

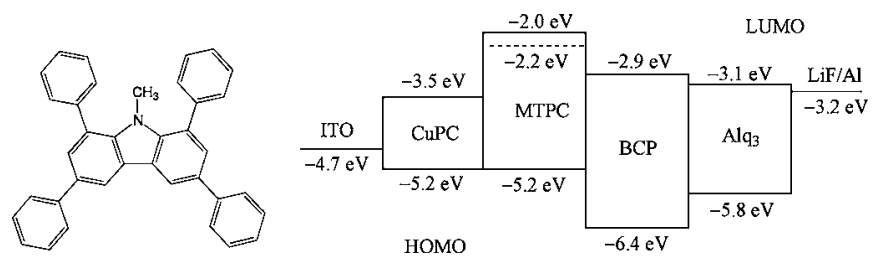

FIG. 1. Chemical structure of MTPC-Me and schematic energy diagrams of organic materials used in this work (HOMO, $-5.2 \mathrm{eV}$; LUMO, $-2.2 \mathrm{eV}$ for NPB). 

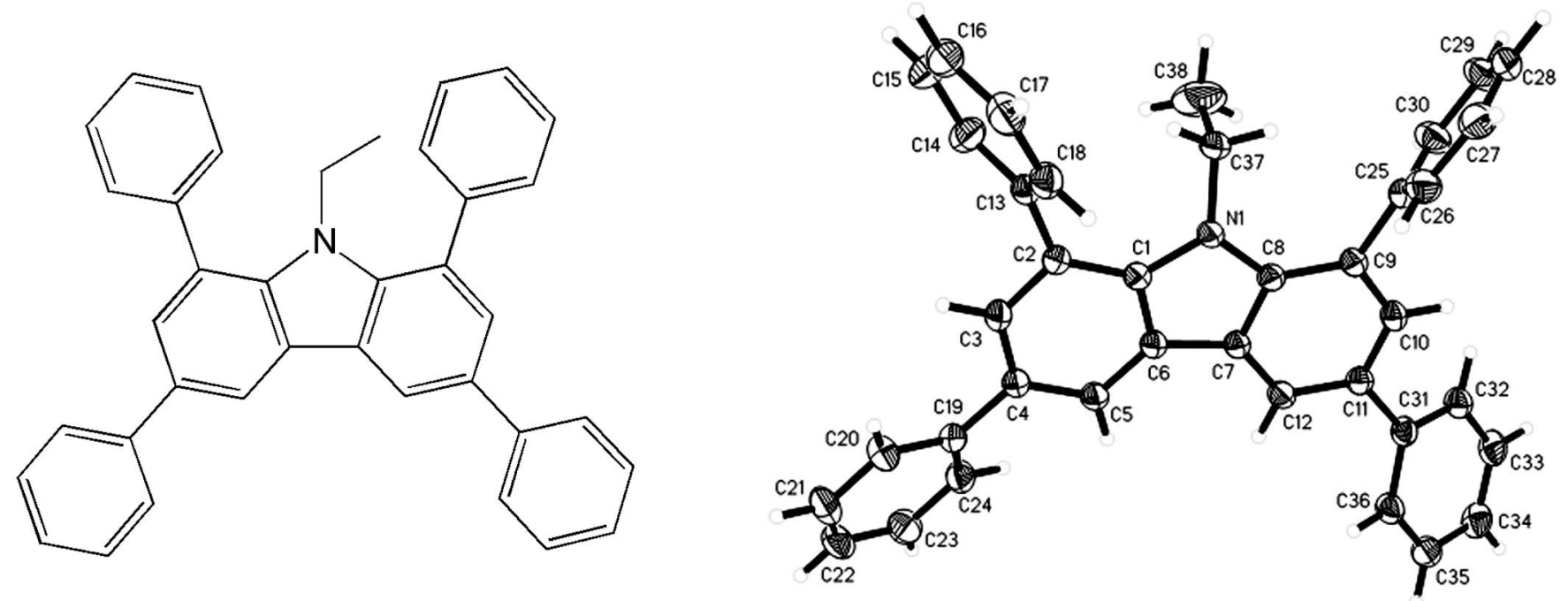

FIG. 2. Chemical structure and crystal structure of MTPC-Et.

star-configured structure and this is essential for this kind of compounds to acquire enough morphological thin-film stability ${ }^{11-14}$ and thermal stability. The decomposition temperature and glass transition $\left(T_{g}\right)$ of MTPC-Me was found to be 351 and $220{ }^{\circ} \mathrm{C}$, respectively. The energy levels calculated using cyclic voltammetric data of this compound are shown in Fig. 1. The energy level of the highest occupied molecular orbital (HOMO, $-5.2 \mathrm{eV}$ ) and lowest unoccupied molecular orbital (LUMO, $-2.0 \mathrm{eV}$ ) of MTPC-Me are comparable to those of NPB (HOMO, $-5.2 \mathrm{eV}$; LUMO $-2.2 \mathrm{eV}$ ). With a large band gap of $3.2 \mathrm{eV}$, MTPC-Me emits a strong n-UV light $\left(\lambda_{\max }=389 \mathrm{~nm}\right.$, decay lifetime $\left.=5.3 \mathrm{~ns}\right)$ with a high photoluminescent (PL) quantum efficiency of $47 \%$ (quinine in $0.05 \mathrm{~mol} / \mathrm{l}$ sulfate as standard) and FWHM of $40 \mathrm{~nm}$ in $\mathrm{CH}_{2} \mathrm{Cl}_{2}$ solution, as depicted in Fig. 3. The PL emission of MTPC-Me film $\left(\lambda_{\max }=395 \mathrm{~nm}\right)$ shows a little redshift from that recorded in $\mathrm{CH}_{2} \mathrm{Cl}_{2}$ solution, presumably this could be attributed to molecular aggregation in the solid state. On the basis of its good thermal and morphological stability, appropriate energy levels, strong n-UV emission, and hole-transporting nature of carbazole-containing compound, MTPC-Me is expected to be a good HTM and EM.

A double-layer device A with MTPC-Me as HTM and $\mathrm{Alq}_{3}$ as EM and ETM was fabricated. For comparison, a

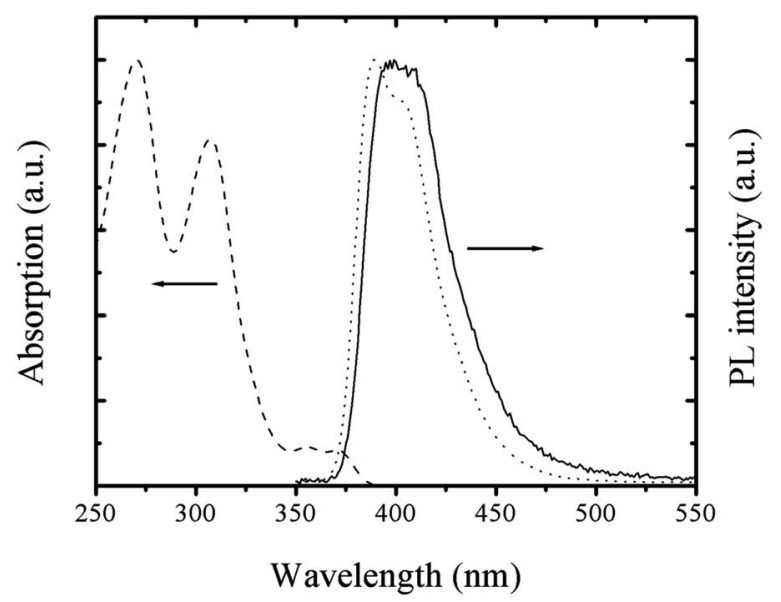

FIG. 3. Absorption (dash line, in $\mathrm{CH}_{2} \mathrm{Cl}_{2}$ ) and $\mathrm{PL}$ emission (dot line, in $\mathrm{CH}_{2} \mathrm{Cl}_{2}$; solid line, thin film) spectra of MTPC-Me. $\mathrm{H}_{2} \mathrm{Cl}_{2}$; solid line, thin film) spectra of MTPC-Me.
Downloaded $27 \mathrm{Apr} 2009$ to 147.8 .17 .95 . Redistribution subject to AlP license or cop standard device B with a similar structure but using NPB as HTM was also fabricated. Similar to the NPB-based device $\mathrm{B}$, the MTPC-Me-based device A gave a green emission with a peak $\left|\lambda_{\max }\right|$ at $530 \mathrm{~nm}$, a characteristic of the emission of $\mathrm{Alq}_{3}$ (Fig. 4), indicating that charge recombination is localized in the $\mathrm{Alq}_{3}$ layer and MTPC-Me acted primarily as a HTM without causing exciton formation at the interface with $\mathrm{Alq}_{3}$. This should be attributed to the appropriate HOMO
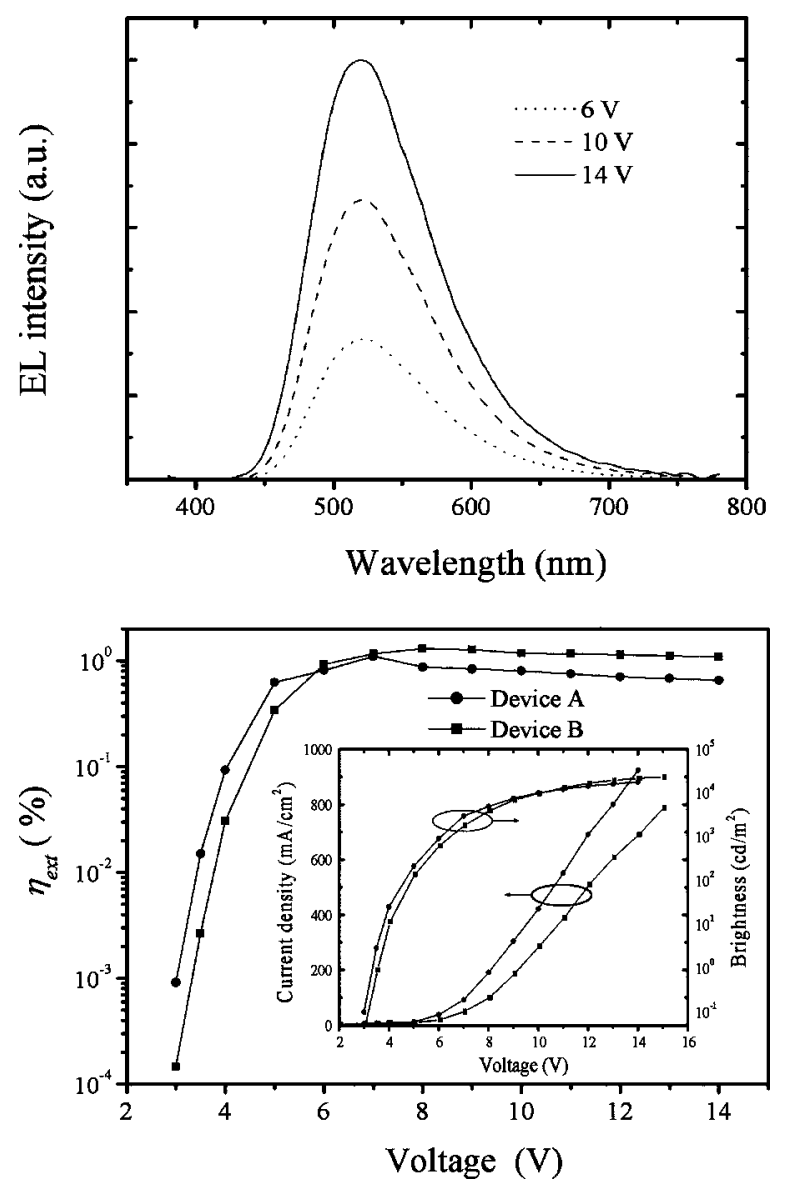

FIG. 4. EL spectrum of device A (top) and external quantum efficiency, current density, and brightness curves (inset) of devices A and B (bottom) vs 

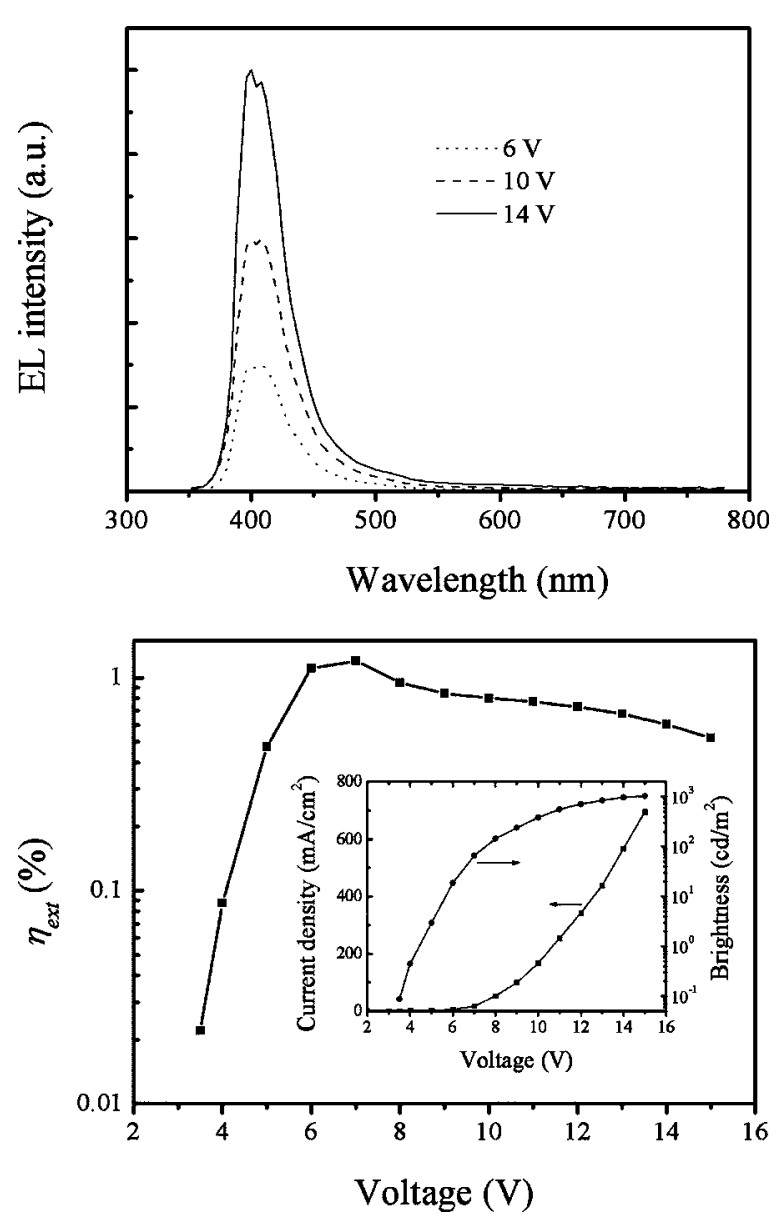

FIG. 5. EL spectrum (top) and external quantum efficiency, current density, and brightness (inset) of device C (bottom) vs the applied voltage.

energy level of MTPC-Me which is favorable for hole injection from ITO to the MTPC-Me and, subsequently, to the $\mathrm{Alq}_{3}$ layer. Similarly, the appropriate LUMO level of MTPC-Me (a bit higher than that of NPB) blocks electron injection from $\mathrm{Alq}_{3}$ to itself. ${ }^{14}$ The electroluminescent (EL) performance of devices A and B are shown in Fig. 4. Both the current density and luminance of the MTPC-Me-based device A are comparable to that of the NPB-based standard device B (Fig. 4). The maximum external quantum efficiency $\left(\eta_{\text {ext }}\right)$, luminous efficiency $\left(\eta_{L}\right)$, brightness, and turn-on voltage $\left(V_{\text {on }}\right)$ of the MTPC-Me-based device A are 1.1\%, $3.3 \mathrm{~cd} / \mathrm{A}, 18000 \mathrm{~cd} / \mathrm{m}^{2}$, and $2.4 \mathrm{~V}$, respectively, comparable to the related values found for NPB-based standard device B (maximum $\eta_{\mathrm{ext}}, \eta_{L}$, brightness, and $V_{\mathrm{on}}$ of $1.3 \%$, $4.0 \mathrm{~cd} / \mathrm{A}$, and $25000 \mathrm{~cd} / \mathrm{m}^{2}$, and $2.3 \mathrm{~V}$, respectively). The hole mobility of MTPC-Me determined by time-of-flight measurement is about $1.9 \times 10^{-4} \mathrm{~cm}^{2} / \mathrm{V} \mathrm{s}$, which is comparable to the value reported for NPB.

In device $\mathrm{C}$, a 10 -nm-thick BCP film was inserted between MTPC-Me and $\mathrm{Alq}_{3}$ to prevent leaking excitons into the $\mathrm{Alq}_{3}$ layer as BCP layer has a high HOMO level compared to $\mathrm{Alq}_{3}$ and would block the passage of holes out of MTPC-Me. Device C gave a pure n-UV EL emission $\left(\lambda_{\max }\right.$, $396 \mathrm{~nm}$ ) with a narrow FWHM of $40 \mathrm{~nm}$, as shown in Fig. 5. The maximum $\eta_{\text {ext }}$, brightness, and $V_{\text {on }}$ of device $\mathrm{C}$ are $1.2 \%, 1040 \mathrm{~cd} / \mathrm{m}^{2}$, and $3.5 \mathrm{~V}$ (Fig. 5), respectively, comparable to that found for CBP (Ref. 7) and TPD-based ${ }^{8,9} \mathrm{n}$-UV OLEDs. Recently, a high-performance n-UV OLEDs with a high $\eta_{\text {ext }}$ up to $3.6 \%$. was reported by using $2,2^{\prime \prime}$-bi-
9, $9^{\prime}$-spirobifluorene (B2) ${ }^{10}$ However, the EL emission from this n-UV OLED extended into visible region $\left(\lambda_{\max }\right.$ $\approx 425 \mathrm{~nm}$ ) and its FWHM broadened to $\sim 70 \mathrm{~nm}$. The $V_{\text {on }}$ of device $\mathrm{C}$ was higher than that of device $\mathrm{A}$ or device $\mathrm{B}$, this would be attributed to the LUMO level of MTPC-Me $(-2.0 \mathrm{eV})$ at higher energy level than that of $\mathrm{BCP}$ $(-2.9 \mathrm{eV})$, resulting in higher energy barrier for electrons to jump into the MTPC-Me layer. This barrier might be reduced by replacing $\mathrm{BCP} / \mathrm{Alq}_{3}$ with a $\mathrm{HBM}$ and ETM of $(1,3,5$ phenylene) tris(1-phenyl-1 $H$-benzimidazole). ${ }^{13}$

In summary, a novel wide-band-gap 1,3,6,8-substituted carbazole derivative with a good thermal stability, a good hole-transporting property, and a stong n-UV emission was prepared and successfully used as an efficient n-UV EM and HTM in OLEDs. Given the fact that the molecular structure and, hence, the electronic properties of MTPC-Me and its derivatives could be varied, the development of highperformance n-UV OLEDs using this kind of compounds is envisaged. The present findings also suggest that MTPC-Me is a potential good host material in electrophosphorescence devices.

This work was supported by the Joint Research Scheme NSFC/RGC (N_HKU 742/04), the University Development Fund (Nanotechnology Research Institute, No. 00600009) of The University of Hong Kong, the Innovation Technology Fund (ITF), Strategic Theme on Nano-Biotechnology, the Strategic Theme on Organic Electronics and RGC of HKSAR (Project Nos. HKU 7158/04E and HKU 200607176144), the Guangdong Province Natural Science Foundation (Grant No. 031805), the Major Program in Key Field of Guangdong Province Government (Grant No. 200303), Science and Technology Program of Shenzhen (Grant No. 2006-2007). We acknowledge Clover \& Sunic Systems, Ltd., for their support with the fabrication system housed at The University of Hong Kong.

${ }^{1}$ C. W. Tang and S. A. VanSlyke, Appl. Phys. Lett. 51, 913 (1987).

${ }^{2}$ M. A. Baldo, D. F. O'Brien, Y. You, A. Shoustikov, S. Sibley, M. E. Thompson, and S. R. Forrest, Nature (London) 395, 151 (1998).

${ }^{3}$ L. S. Hung and C. H. Chen, Mater. Sci. Eng., R. 39, 143 (2002).

${ }^{4}$ S. R. Forrest, Nature (London) 428, 911 (2004).

${ }^{5}$ D. F. O'Brien, M. A. Baldo, M. E. Thompson, and S. R. Forrest, Appl. Phys. Lett. 74, 442 (1999).

${ }^{6}$ R. J. Holmes, B. W. D'Andrade, S. R. Forrest, X. Ren, J. Li, and M. E. Thompson, Appl. Phys. Lett. 83, 3818 (2003).

${ }^{7}$ L. Zou, V. Savvate'ev, J. Booher, C. H. Kim, and J. Shinar, Appl. Phys. Lett. 79, 2282 (2001)

${ }^{8}$ K. Okumoto and Y. Shirota, Appl. Phys. Lett. 79, 1231 (2001).

${ }^{9}$ C. F. Qiu, L. D. Wang, H. Y. Chen, M. Wong, and H. S. Kwok, Appl. Phys. Lett. 79, 2276 (2001).

${ }^{10}$ T. C. Chao, Y. T. Lin, C. Y. Yang, T. S. Hung, H. C. Chou, C. C. Wu, and K. T. Wong, Adv. Mater. (Weinheim, Ger.) 17, 992 (2005).

${ }^{11}$ K. Brunner, A. Dijken, H. Borner, J. J. A. M. Bastiaansen, N. M. M. Kiggen, and B. M. W. Langeveld, J. Am. Chem. Soc. 126, 6035 (2004).

${ }^{12}$ M. H. Tsai, Y. H. Hong, C. H. Chang, H. C. Su, C. C. Wu, A. Matoliukstyte, J. Simokaitiene, S. Grigalevicius, J. V. Grazulevicius, and C. P. Hsu, Adv. Mater. (Weinheim, Ger.) 19, 862 (2007).

${ }^{13}$ P. Kundu, K. R. J. Thomas, J. T. Lin, Y. T. Tao, and C. H. Chien, Adv. Funct. Mater. 13, 445 (2003).

${ }^{14}$ J. Y. Li, D. Liu, Y. Q. Li, C. S. Lee, H. L. Kwong, and S. T. Lee, Chem. Mater. 17, 1208 (2005).

${ }^{15}$ C. M. Che, S. C. Chan, H. F. Xiang, M. C. W. Chan, L. Yu, and Y. Wang, Chem. Commun. (Cambridge) 2004, 1484.

${ }^{16}$ H. F. Xiang, S. C. Chan, K. K. Y. Wu, C. M. Che, and P. T. Lai, Chem. Commun. (Cambridge) 2005, 1408. 